\title{
Redistribuição fiscal para o desenvolvimento turístico local e regional
}

\author{
Giuliano Alves Borges e Silva \\ Universidade de São Paulo (USP) / Centro de Estudos em Gestão e Políticas Públicas \\ Contemporâneas (GPUBLIC), Faculdade de Economia, Administração e Contabilidade de \\ Ribeirão Preto (FEA-RP) \\ Ribeirão Preto / SP - Brasil \\ João Luiz Passador \\ Universidade de São Paulo (USP) / Centro de Estudos em Gestão e Políticas Públicas \\ Contemporâneas (GPUBLIC), Faculdade de Economia, Administração e Contabilidade de \\ Ribeirão Preto (FEA-RP) \\ Ribeirão Preto / SP - Brasil
}

\begin{abstract}
O federalismo municipalista é um modelo descentralizador de políticas, porém possui distorções no que tange à distribuição de receitas e ao porte dos municípios. Entre essas políticas, destaca-se a promoção do turismo. Poucos estados procuram efetivamente redistribuir receitas, o que leva ao seguinte objetivo: analisar a redistribuição do imposto - ICMS Turístico — como política de descentralização, considerando o tamanho dos municípios. O artigo mescla métodos quantitativos para verificar a relação entre competividade e dependência turística com investimento em turismo, além de métodos qualitativos contendo detalhamento de oito municípios. O objeto de análise é o estado de Minas Gerais, pioneiro em redistribuir a arrecadação de um imposto para os municípios turisticamente organizados. Os resultados apontam para o significativo grau de contribuição ao desenvolvimento, principalmente entre os municípios de grande porte com critérios de aplicabilidade limitados nas pequenas cidades. O modelo de redistribuição adotado pelo ICMS Turístico pode se tornar uma solução viável para os problemas do pacto federativo no Brasil.
\end{abstract}

Palavras-chave: federalismo; redistribuição fiscal; turismo; Minas Gerais; municípios.

Devolución fiscal para el desarrollo del turismo local y regional

Entre las diversas posibilidades de las políticas de descentralización en el contexto brasileño, hacemos hincapié en la promoción del turismo. El estado de Minas Gerais fue pionero en redistribuir la recau-

DOI: http://dx.doi.org/10.1590/0034-7612150785

Artigo recebido em 11 jun. 2015 e aceito em 20 abr. 2016.

(c) (1) 
dación de un impuesto a los municipios turísticamente organizados. Trabajos académicos analizan el contexto de la distribución del impuesto, desde el punto de vista de una política del gobierno, pero no hay evidencia empírica de casos positivos. El objetivo de este estudio fue analizar la eficacia del impuesto - ICMS Turístico - como política de gobierno local y de descentralización, teniendo en cuenta el tamaño de los municipios. Los resultados muestran que la política es apropiada, especialmente entre en las municipalidades grandes, y con una eficacia limitada en las pequeñas ciudades.

Palabras clave: federalismo; devolución; turismo; Minas Gerais; municipalidades.

Fiscal redistribution in favor of the development of local and regional tourism

Municipalist federalism is a model that decentralizes policies, although it does have certain distortions in terms of the distribution of revenues and the contribution of the municipalities. Promoting tourism is one of these policies that deserves highlighting. Few states effectively seek to redistribute their revenues, which leads us to the following objective: to analyze the redistribution of the tax known as the ICMS Turístico as a policy of decentralization, considering the size of the municipalities. This article combines quantitative methods in order to verify a relationship between competitiveness and tourism dependence with investments in tourism, as well as qualitative methods detailing eight municipalities in particular. The object of this analysis is the state of Minas Gerais, a pioneer in redistributing its revenues from a tax on municipalities focused on tourism. The results show a significant contribution to development, especially among the larger municipalities with the criteria of applicability more limited in the smaller towns. The model of redistribution adopted in the form of the ICMS Turístico may prove a viable solution to the problems of the federative pact in Brazil.

KEYwords: federalism; fiscal redistribution; tourism; Minas Gerais state; municipalities.

\section{Introdução e justificativa}

A organização do Estado brasileiro está fundamentada no federalismo municipalista. Internacionalmente, essa característica de empoderamento das instituições locais (estados e municípios) é única. Com isso, a Constituição brasileira de 1988 permitiu aos governos locais a formulação e aplicação de uma vasta gama de políticas sociais e econômicas próprias do interesse regional (Borges, 2011).

Entre as diversas possibilidades de políticas descentralizadoras, destacamos que a promoção do turismo é responsabilidade compartilhada pela União, estados e municípios. A autonomia entre os entes federativos atribui responsabilidades, mas nem sempre os recursos financeiros são distribuídos na mesma proporção porque o governo central detém a maior parte da arrecadação, seguido pelos governos estaduais e por último os municípios (Oliveira, Marques-Junior e Lagemann, 2012).

Por isso, as ações governamentais que visam distribuir maiores receitas aos municípios são relevantes, afinal é ali que a cidadania é exercida (Wampler, 2012). Nesse sentido, o estado de Minas Gerais foi pioneiro na redistribuição da arrecadação de um imposto estadual, o Imposto sobre Circulação de Mercadorias e Prestação de Serviços (ICMS), para os municípios com adequada organização da atividade turística. 
Essa distribuição de receitas para os municípios trabalharem sua gestão turística pode ser considerada uma política inovadora porque é única no Brasil. Consideramos a inclusão do turismo na Lei estadual no $18.030 / 2009$ um instrumento democrático para melhor distribuição de renda, pois sua atividade permite, a todos os setores envolvidos, diversos benefícios substanciais em termos econômicos, culturais e sociais (Minas Gerais, 2009).

Analisar, avaliar e aprimorar políticas públicas voltadas para a redistribuição vertical de receitas constitui um caminho palpável para a melhoria da governança. A análise de externalidades fiscais verticais (de governos centrais para os descentralizados) possui vasta literatura internacional, com destaque para Flowers (1988), Hoyt e Jensen (1996), Hoyt (2001), Keen e Kotsogiannis (2002), Fredriksson e Mamun (2008), que enfatizam a força do governo central sobre outros, porém com poucas evidências empíricas; enquanto Besley e Rolsen (1998) e Oliveira, Marques-Júnior e Lagemann (2012) apresentam circunstâncias empíricas sobre externalidades verticais fiscais em contextos distintos.

Até o presente momento, nenhum trabalho acadêmico evidenciou tais externalidades a partir de experiências positivas de redistribuição tributária. Desse modo, a análise sobre a redistribuição do ICMS turístico do estado de Minas Gerais avança nos estudos sobre federalismo porque trata de uma política pública sui generis para o desenvolvimento local e regional do turismo numa unidade federativa do Brasil que foi criada há sete anos, cuja prática necessita de avaliações, com possibilidades de ser adotada por outros estados do Brasil e até mesmo outros países federalistas.

Mais especificamente, buscaremos responder à seguinte questão: é possível desenvolver o turismo local e regional com recursos arrecadados de um imposto e redistribuídos para essa finalidade?

O objetivo central que orienta a pesquisa consiste em analisar o ICMS Turístico como política de descentralização, considerando as características próprias dos municípios de pequeno, médio e grande porte. Para isso, a estruturação do trabalho conta com: (2.1) breve referencial teórico que abarca o tema federalismo e políticas públicas; (2.2) caracteriza as chamadas externalidades horizontais e verticais; (2.3) destaca a produção científica existente acerca do objeto de estudo; (3) descreve os procedimentos metodológicos; (4.1) apresentação da Política de ICMS Turístico; (4.2) mostra resultados quantitativos de correlação por grupo de municípios; (4.3) elucida quadro resumo qualitativo e documental; (5) apresenta considerações finais.

\section{Referencial teórico}

Ressaltamos que a maior contribuição e escopo do trabalho são amparados pelos resultados empíricos apresentados. As temáticas abordadas neste tópico norteiam abordagens sobre o Federalismo, com principal foco em situar o pano de fundo da pesquisa, além de caracterizar as externalidades horizontais e verticais. Buscamos, ainda, evidenciar a produção científica sobre políticas públicas, circuitos turísticos, descentralização e regionalização do turismo. 


\subsection{Federalismo e políticas públicas}

O modelo original brasileiro é caracterizado pela coexistência da dupla soberania União-estado, impulsionado por experiências bem-sucedidas, onde a autonomia política das unidades menores (entes federativos) fica sob a égide de uma autoridade superior (governo federal). Porém, a federação brasileira é a única do mundo a possuir três níveis federativos: União, estados e municípios (Camargo, 2004).

De fato, o Brasil seguiu uma tendência internacional de adoção do federalismo, adaptando-o à sua realidade. Essa configuração aproxima o poder das comunidades, mas também exige capacidades específicas de gestão aos representantes do administrativo em face da forte desigualdade com a qual se deparam, acarretando a necessidade de um planejamento regional eficiente, tendo em vista a grande dependência dos municípios, principalmente os pequenos, pelas transferências intergovernamentais (Silva et al., 2015a).

Duas formas básicas de organização político-administrativa prevalecem na maioria dos países: a federação e o Estado unitário. Atualmente, o Brasil é caracterizado como uma federação de estados autônomos (Barbosa, 1998). Apesar do regime federalista que naturalmente apresenta proposta descentralizadora, Arretche (2012) defende que o sistema brasileiro, na prática, apresenta contornos centralizadores - forte presença da União -; entretanto, estados e municípios devem exercer protagonismo na formulação e implementação de políticas públicas.

Nesse sentido, ambos os modelos não podem ser considerados estáticos. Mesmo nos países que adotam uma forma unitária, existe certo grau de descentralização na estrutura do governo, enquanto países federalistas podem apresentar alguma centralização (Barbosa, 1998).

Tal dualidade ocorre em razão das dificuldades de concretização de políticas públicas. Por um lado, estados unitários estão distantes de seus cidadãos e por isso sofrem para alocar recursos adequadamente. Por outro, federações descentralizadas apresentam unidades federativas com dificuldades de planejamento.

Em especial, os municípios pequenos possuem dificuldades em estabelecer políticas locais, tendo em vista falta de quadros técnicos e limitações de planejamento, o que implica falta de arrecadação, formulação e concretização de políticas públicas. Ao invés de projetos e programas duradouros, nesses locais, configura-se um quadro de clientelismo e mandonismo, com elevado grau de dependência de transferências intergovernamentais e, contraditoriamente, alto desempenho nos índices de gestão (Klering, Kruel e Stranz, 2012).

Isso ajuda a explicar por que o Brasil, organizado por um federalismo municipalista, concentra a maior parte das receitas orçamentárias na União, mesmo depois de contabilizadas as transferências intergovernamentais (Ferreira e Bugarin, 2007).

O presente estudo verifica a redistribuição de um imposto estadual para municípios, enquanto ferramenta para o desenvolvimento de políticas públicas de turismo, num evidente exemplo de descentralização administrativa, o que requer tal contextualização acerca do federalismo brasileiro. 
Já a noção de políticas públicas está ligada conceitualmente à formulação de ideias, arranjos institucionais e interesses envolvidos na resolução de problemas políticos. É mais do que prover benefícios ou regular danos; trata-se de escolhas, criação de processos, os compromissos que mostram as prioridades governamentais, e por isso a gestão das políticas públicas constitui um componente essencial da relação Estado-sociedade, incluindo as decisões sobre aplicações de recursos (May e Jochim, 2013).

O propósito central da política pública é resolver os problemas sociais mediante coordenação da ação coletiva. Alguns autores defendem que a sociedade civil deve participar da elaboração, gestão e execução das políticas e principalmente do controle social, e a solução encontrada muitas vezes é a descentralização de políticas para os municípios (Silva et al., 2015b).

Isso porque a efetivação de direitos modifica a vida dos indivíduos. Esses personagens são denominados atores. As formas de participação englobam os conselhos, movimentos sociais e organizações, mas geralmente os papéis formulação e aplicação são mesmo efetivados pelo Estado em seus três níveis de governo. Nesse caso, todas as ações e omissões governamentais devem ser consideradas porque elas influenciam o cotidiano da população (Carter et al., 2015).

A política de implantação do ICMS Turístico segue todos os preceitos teóricos abordados até aqui. Preliminarmente, consideramos que ela possui capacidade de impacto, sua natureza visa descentralizar políticas do estado para as cidades, além de incentivar a organização dos munícipes em torno de uma política de gestão do turismo.

\subsection{Políticas verticais e horizontais de distribuição de receita}

Outro contexto teórico que merece destaque é a definição exata sobre o tipo de política pública que o ICMS Turístico representa. Do ponto de vista estadual, a concessão de receitas para um ente federativo menor representa uma política vertical com descentralização da receita orçamentária. É necessário destacar esse aspecto, porque o que está em discussão é a política estadual. Caso o trabalho se referisse à competição entre os municípios por uma parcela maior do imposto, estaríamos tratando de uma competição tributária horizontal, onde entes federativos de um mesmo nível disputam, entre si, uma posição melhor na divisão do "bolo".

Os estudos negativos sobre externalidades horizontais propõem que os tributos e as correspondentes arrecadações tendem a ser baixos quando há concorrência entre os governos de mesmo nível por investimentos e crescimento econômico. Nesse caso, a arrecadação não é distribuída de modo equânime e há provisão insuficiente de bens públicos. No Brasil, essa situação é amplamente estudada sob o enfoque da "guerra fiscal" (Oliveira, Marques-Júnior e Lagemann, 2012).

Por outro lado, quando há uma regulamentação adequada e a concorrência contribui para maior organização do ente federativo, é possível enxergar aspectos vantajosos. Salientamos que tal situação depende de políticas estruturais, sistêmicas e duradouras de desenvolvimento (Silva et al., 2015a). 
O caso do ICMS turístico chama atenção entre as políticas verticais, porque ele não é uma competição tributária. Ao contrário, é uma distribuição dada pelo merecimento de cada ente federativo menor, daí a inovação da prática e seu aspecto positivo. Keen e Kotsogiannis (2002) argumentam que a concorrência vertical por tributos ocorre quando os governos centrais disputam a parcela do bolo com os entes menores.

O processo das políticas envolve uma infinidade de interações complexas. Isto é, os atores, o contexto e os resultados; tais interações podem gerar diversos focos de pesquisa. $\mathrm{O}$ estudo do conteúdo das políticas é um deles, e ajuda a entender melhor sobre a criação e as regras das políticas (Weible, 2014).

Primeiramente, destacamos o estudo do conteúdo das políticas. Essa metodologia de análise indica que devemos descrever a gênese, o desenvolvimento e a operação das políticas públicas, bem como os processos e as regras de execução. Nesse sentido, os governos precisam verificar esses aspectos para entender a efetividade da política e o contexto para a qual foram criadas (May e Jochim, 2013).

Por outro lado, é necessária também uma avaliação crítica das avaliações. Muitas vezes realizada por pesquisadores, esse tipo de análise verifica a eficácia dos indicadores de avaliação utilizado em políticas, ou ainda o método e os relatórios de avaliação desenvolvidos pelos governos (Patton, 1982).

As linhas qualitativas de análise são mais relacionadas com processos e conteúdos, ao passo que as quantitativas, aos indicadores, impactos e resultados. Independentemente do tipo de análise, é possível afirmar que os programas precisam ser constantemente avaliados para que as mudanças sociais desejadas sejam realmente implementadas.

As duas formas escolhidas são difundidas na literatura, com maior espaço para o estudo do conteúdo das políticas. No entanto, o objeto de estudo requer que os indicadores do ICMS Turístico sejam avaliados, por isso a escolha de ambas as formas casa perfeitamente com o escopo do trabalho.

\subsection{Circuitos turísticos e políticas de turismo no ambiente federalista}

Entre os aspectos teóricos relevantes para o contexto do estudo, resta identificar os limites da produção científica acerca do objeto de estudo. Isso inclui revisão sobre: políticas públicas de turismo, políticas de descentralização e regionalização do turismo, e produções sobre circuitos turísticos. Em especial, sistematizar as que apresentam ênfase empírica relacionada com o estado de Minas Gerais, com intuito de posicionar as contribuições à literatura, apresentadas no decorrer do trabalho.

O planejamento de políticas de turismo passou a ser considerado atividade fundamental para o Estado a partir da década de 1960, na Europa, apresentando abordagem urbanística, principalmente para a criação de infraestrutura e utilização adequada do solo (Pereira, 1999).

No entanto, com a crescente demanda de turistas internacionais, e o percentual produtivo gerado por tal grupo, houve, como consequência, o avanço contundente de políticas de 
turismo nacionais, relegando, inicialmente, a formação de políticas nas esferas subnacionais, "negligenciando os efeitos ambientais e socioculturais causados pela atividade" (Gomes e Santos, 2007:74).

Em contraposição, a corrente regionalista considera que o planejamento e a colaboração descentralizada tendem a aumentar a capacidade do turismo em gerar bem-estar para as comunidades (Shone e Memon, 2008). Nesse sentido, Silva e colaboradores (2015b) chamam atenção quanto ao papel do setor público ante a necessidade de descentralização das políticas de turismo, tendo em vista, também, que a divisão federalista não apenas permite, como preconiza tal circunstância.

Embora a participação do setor privado nas atividades turísticas seja visível e natural, é preciso considerar a qualidade de vida das comunidades receptoras como o primeiro objetivo do turismo (Cabrera, 2002). Em contextos de comunidades pequenas e desarticuladas, fica evidente a necessidade de cooperação entre agentes e locais, como solução equalizadora para o desenvolvimento de políticas regionais de turismo.

O embrião dos chamados "circuitos turísticos" parte dessa concepção. Nem toda localidade congrega atrativos suficientes para se desenvolver como destino turístico, dependendo, muitas vezes, do trabalho cooperado com uma região dotada de atrativos similares e complementares (Bahl, 2004).

A regionalização do turismo, naturalmente orientada para uma identidade local, depende de articulação política, capaz de conciliar características regionais para uma linguagem global que atraia público suficiente à manutenção da atividade conjunta. Isso esbarra em muitas dificuldades; a principal delas é que normalmente as oportunidades de mercado e investimento encontram-se nos grandes centros. Os locais possuem dificuldades em criar estratégias de lazer e acessibilidade. Além disso, a infraestrutura precisa ser aprimorada (Chang, 1998; Dredge e Jenkins, 2010).

Por esse motivo, a formação de circuitos articulados é considerada uma alternativa viável. Então, é preciso valorizar o contexto histórico da atividade turística, fortalecer as histórias locais e reforçar a autoestima e a atitude dos residentes (Réau, 2015).

Da perspectiva institucional, políticas de regionalização do turismo, como é o caso dos circuitos turísticos, foram possíveis a partir da década de 1990, pelo Plano Nacional de Municipalização do Turismo (PNMT), em que o governo federal delimitou a atuação do setor privado e distribuiu responsabilidades para estados e municípios, incentivando o desenvolvimento dos Conselhos Municipais de Turismo. Com isso, a obrigatoriedade de organização municipal em torno do turismo passa a ser uma exigência fundamental para a transferência de recursos entre entes federativos (Gomes e Santos, 2007).

Mesmo com a possibilidade de transferência de recursos da União e de estados para municípios tendo sido reconhecida desde 1988, apenas o estado de Minas Gerais realiza a redistribuição do ICMS para as localidades com adequada organização da atividade turística. Por isso, tem sido objeto de estudo na academia. O quadro 1 apresenta o estado da arte que resume contribuições teórico-empíricas, tendo como objeto Circuitos Turísticos de Minas Gerais. 


\section{Estado da arte acerca do objeto de estudo}

\begin{tabular}{|c|c|c|}
\hline Autores & Objetivo & Principais Considerações \\
\hline $\begin{array}{l}\text { Gomes, Silva e Queiroz- } \\
\text { Neto (2006) }\end{array}$ & $\begin{array}{l}\text { Realizar revisão de literatura para contextualiza- } \\
\text { ção das políticas públicas de turismo no Brasil, } \\
\text { enfatizando o estado de Minas Gerais. }\end{array}$ & $\begin{array}{l}\text { O tamanho do circuito, bem como a cooperação } \\
\text { entre eles, são responsáveis pelo êxito e participação } \\
\text { dos membros. }\end{array}$ \\
\hline $\begin{array}{l}\text { Emmendoerfer e cola- } \\
\text { boradores (2007) }\end{array}$ & $\begin{array}{l}\text { Analisar a formação dos circuitos turísticos } \\
\text { como política pública para o desenvolvimento } \\
\text { do turismo. }\end{array}$ & $\begin{array}{l}\text { A governança sociopolítica dos circuitos turísticos } \\
\text { em Minas Gerais apresenta estrutura híbrida diante } \\
\text { das ações de regionalização do estado. }\end{array}$ \\
\hline Gomes e Santos (2007) & $\begin{array}{l}\text { Verificar a influência da Política de Circuitos } \\
\text { Turísticos nos comportamentos dos agentes e } \\
\text { nas transações. }\end{array}$ & $\begin{array}{l}\text { A política de circuitos turísticos de Minas Gerais criou } \\
\text { uma estrutura de governança, que possibilitou um } \\
\text { aumento da frequência das relações entre agentes } \\
\text { e reduziu a incerteza. }\end{array}$ \\
\hline $\begin{array}{l}\text { Emmendoerfer, Silva e } \\
\text { Lima (2011) }\end{array}$ & $\begin{array}{l}\text { Analisar os Circuitos Turísticos da perspectiva da } \\
\text { inovação social. }\end{array}$ & $\begin{array}{l}\text { As inovações sociais presentes na gestão do turismo } \\
\text { em Minas Gerais são evidentes: gestão compar- } \\
\text { tilhada entre o poder público e a sociedade civil; } \\
\text { promoção do turismo sustentável; e preservação e } \\
\text { resgate dos patrimônios culturais e naturais. }\end{array}$ \\
\hline $\begin{array}{l}\text { Silva e colaboradores } \\
(2012)\end{array}$ & $\begin{array}{l}\text { Avaliar a política de Circuitos Turísticos de Minas } \\
\text { Gerais, na perspectiva dos agentes estratégicos. }\end{array}$ & $\begin{array}{l}\text { Há uma boa integração entre cidades no planeja- } \\
\text { mento turístico regional, porém a principal dificul- } \\
\text { dade é a sustentabilidade financeira dos circuitos. }\end{array}$ \\
\hline $\begin{array}{l}\text { Soares e colaboradores } \\
(2012)\end{array}$ & $\begin{array}{l}\text { Analisar a participação social induzida pelo ICMS } \\
\text { Turístico e Conselhos Municipais de Turismo. }\end{array}$ & $\begin{array}{l}\text { Maior participação social, porém ICMS Turístico } \\
\text { e Conselhos Municipais apresentam limitações } \\
\text { administrativas e operacionais. }\end{array}$ \\
\hline $\begin{array}{l}\text { Soares, Emmendoerfer } \\
\text { e Monteiro (2013) }\end{array}$ & $\begin{array}{l}\text { Analisar o Planejamento Estratégico de Turismo } \\
\text { Estadual. }\end{array}$ & $\begin{array}{l}\text { Apresenta avanços na condução política, porém } \\
\text { limitações na gestão e operacionalização. }\end{array}$ \\
\hline Fuchs e Oliveira (2013) & $\begin{array}{l}\text { Identificar os resultados obtidos com a aplicação } \\
\text { do critério ICMS turismo junto à política redistri- } \\
\text { butiva de Minas Gerais no período de janeiro a } \\
\text { dezembro de } 2011 \text {. }\end{array}$ & $\begin{array}{l}\text { Foram organizados e discutidos os apontamentos } \\
\text { obtidos com a redistribuição do ICMS a partir do } \\
\text { critério turismo. }\end{array}$ \\
\hline $\begin{array}{l}\text { Sette, Valle e Coutinho } \\
\text { (2015) }\end{array}$ & $\begin{array}{l}\text { Estudar uma política de regionalização do } \\
\text { turismo. }\end{array}$ & $\begin{array}{l}\text { O reconhecimento da política de regionalização } \\
\text { mineira como uma estratégia de sucesso. Porém, } \\
\text { apontam certa dificuldade no desenvolvimento de } \\
\text { ações que resultem em benefícios práticos em } \\
\text { curto prazo. }\end{array}$ \\
\hline
\end{tabular}

Fonte: Elaborado pelos autores.

Diversos trabalhos analisados demonstram a relevância da política — sob o enfoque contextual, de governança sociopolítica, dos agentes participantes, inovação e participação social —, no entanto, apenas Fuchs e Oliveira (2013) enfatizam a redistribuição vertical de receitas tributárias. A principal limitação do referido trabalho é a ausência de resultados em- 
píricos sobre a dependência dos municípios beneficiados em relação à atividade turística, para balizar uma adequada avaliação do ICMS Turístico como instrumento de descentralização de políticas por meio das Associações de Circuitos Turísticos.

Um dos avanços do presente consiste na análise pormenorizada pelo tamanho dos municípios beneficiados, diante da evidência teórico-empírica de que os pequenos municípios possuem maior dificuldade de planejamento de políticas em relação aos grandes, porém melhor performance de gestão (Arretche, 2012; Klering, Kruel e Stranz, 2012).

\section{Procedimentos metodológicos}

Como o trabalho objetiva analisar o ICMS Turístico enquanto política de descentralização, considerando as características próprias dos municípios de pequeno, médio e grande porte, fica clara a natureza explicativa do estudo. Diante da finalidade, parece oportuna a combinação de métodos qualitativos e quantitativos para o estudo.

A escolha do estado de Minas Gerais como objeto de análise ampara-se em diversos motivos. O principal deles, único estado entre os 27 da federação a adotar política vertical e fiscal de apoio ao turismo local. O estado, localizado na Região Sudeste do Brasil (figura 1), é o estado com maior número de municípios do Brasil, ao todo 853, dos quais 158 foram analisados por terem recebido repasse de ICMS Turístico no ano de 2014. Além disso, é o quarto em área territorial $\left(586.519,727 \mathrm{~km}^{2}\right)$, segundo em termos populacionais (19.597.330 habitantes), terceiro em PIB (Produto Interno Bruto), com inegável contribuição histórica, social, cultural e econômica no contexto nacional, além de inúmeras qualificações em potencial turístico, com vocações gastronômicas, religiosas, artesanais, culturais, patrimoniais e tantas outras (IBGE, 2010).

A primeira etapa dos resultados diz respeito a formulação, legislação e regras para participação na política, e o instrumento de coleta de dados oportuno foi a pesquisa documental da legislação e dos critérios de participação. Os principais documentos estudados constam como Minas Gerais (2009) e Minas Gerais/Setur (2015), principalmente o site oficial do Observatório Estadual do Turismo (<www.minasgerais.com.br/observatorioturismomg >).

A segunda etapa utiliza-se de métodos quantitativos. Nesse caso, o teste de correlação de Pearson foi escolhido com intuito de verificar se, entre os municípios organizados para recebimento do ICMS turístico, aqueles que vinculassem alta competitividade turística (IC) somada ao alto grau econômico de dependência do turismo (ID) são, de fato, os municípios com menos benefícios, que são baseados no Índice Relativo de Investimento em Turismo (IIT) criado pelo governo do estado. Salientamos que a correlação esperada para que a política seja considerada efetiva tenha sinal negativo, porque os municípios com menor receita por habitante e menor dependência econômica devem ter maior benefício fiscal, ou seja, esperamos a correlação negativa.

O teste foi repetido por quatro vezes, sendo uma vez para cada categoria de município, conforme Firjan (2014) (tabela 1). 

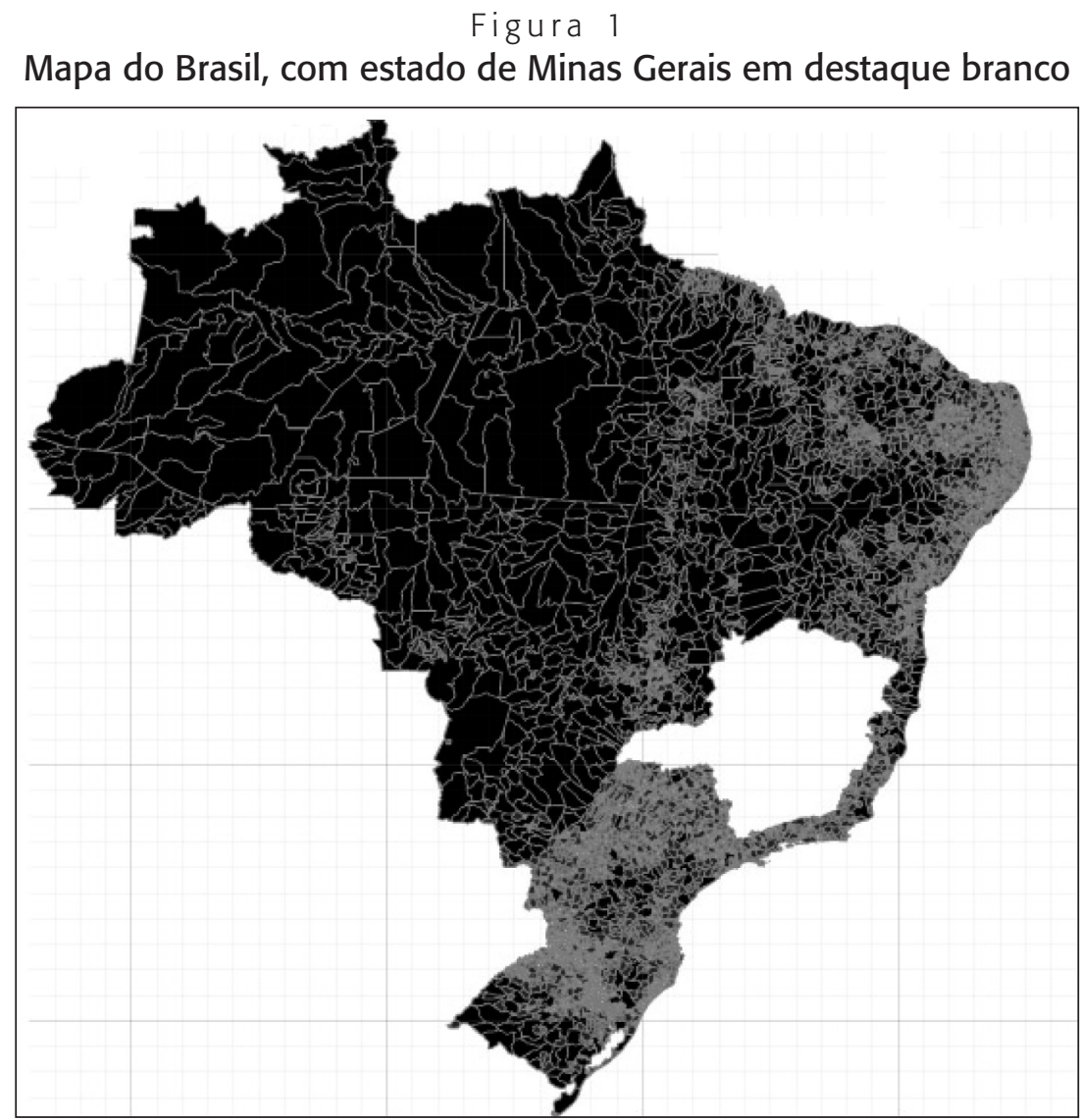

Fonte: IBGE (2010).

Tabela 1

Classificação municipal quanto ao porte populacional e amostra

\begin{tabular}{|lll|}
\hline Pequeno porte I & Até 20.000 habitantes & 111 municípios beneficiados \\
Pequeno porte II & 20.001 a 50.000 habitantes & 25 municípios beneficiados \\
Médio porte & 50.001 a 100.000 habitantes & 9 municípios beneficiados \\
Grande porte & 100.001 a 900.000 habitantes & 13 municípios beneficiados \\
\hline
\end{tabular}

Fonte: Firjan (2014).

A coleta dos dados secundários para a segunda etapa foi dividida em seis passos, todos executados no programa Microsoft Excel 2010:

1. Lista dos 158 Municípios beneficiados e IIT fornecido - Fonte de dados: Governo do Estado de Minas Gerais/Setur (Secretaria de Turismo);

2. Pesquisa população total de habitantes em cada município — Fonte: IBGE (2010); 
3. Pesquisa IC de cada município - Fonte: Governo do Estado de Minas Gerais/Setur — Secretaria de Turismo (Minas Gerais/Setur, 2015);

4. Pesquisa ID de cada município - Fonte: a partir de IBGE (2010);1

5. Soma "ID + IC";

6. Correlaciona (Soma “ID + IC") com IIT em grupos separados por classificação municipal.

A terceira e última etapa retorna ao método qualitativo. Realizamos uma pesquisa documental, principalmente em dados da Setur e site dos municípios, e montamos um quadro com as cidades em condições extremas, salientando as características turísticas de oito municípios (maior e menor "ID + IC" de cada grupo).

\section{Resultados e discussões}

\subsection{Estudo do conteúdo da Política de ICMS Turístico}

O ICMS Turístico foi regulamentado pela Lei ㄲo 18.030 de 2009. Atua como motivador e catalisador de ações, visando estimular a formatação e implantação, por parte dos municípios, de programas e projetos voltados para o desenvolvimento turístico sustentável (Minas Gerais, 2009).

É um incentivo que tem o objetivo de que as cidades se organizem para o turismo e o pagamento é feito a cada município que atinja a critérios predeterminados (tabela 2).

O pagamento é proporcional ao IIT, que é calculado pela seguinte fórmula: Nota da cidade (tabela 2) $\times$ IRC (Indicador da Receita Corrente). Na fórmula, quanto maior a RCL per capita, menor o IRC (tabela 3), por isso o multiplicador gera um número em que, quanto menor a RCL, maior será o IIT, e, consequentemente, mais benefícios fiscais a cidade deve receber.

\section{Tabela 2}

\section{Obrigações de organização do município}

\begin{tabular}{|lc|}
\hline \multicolumn{1}{|c|}{ Critério } & Nota Máxima \\
\hline Participar de um circuito turístico reconhecido pela Setur, nos termos do Programa de Regionalização & 4 \\
do Turismo no Estado de Minas Gerais. & 2,5 \\
Ter elaborada e em implementação uma política municipal de turismo. & 1 \\
Possuir Conselho Municipal de Turismo (Comtur), constituído e em regular funcionamento. & 1 \\
Possuir Fundo Municipal de Turismo (Fumtur), constituído e em regular funcionamento. & 0,75 \\
Ter reconhecida proteção ao patrimônio cultural. & 0,75 \\
Ter reconhecida proteção ao meio ambiente. & \\
\hline
\end{tabular}

Fonte: Minas Gerais (2009).

\footnotetext{
${ }^{1}$ O ID soma a proporção de empregos gerados em atividade de turismo em relação a todas as ocupações com a proporção de empresas cadastradas em atividades turísticas diante de todas as empresas cadastradas no local. Após tal soma, divide-se o número por 2 para encontrar o ID do local. Assim, é um índice que mede o grau de dependência do turismo.
} 
Vale ressaltar alguns aspectos sobre os critérios estabelecidos em lei. O estado possui 45 circuitos turísticos, com 417 municípios habilitados à solicitação do ICMS Turístico. As três ideias seguintes dependem da capacidade de organização da cidade em torno do turismo (implantar política, conselho e fundo municipal), tal qual defendem Carter e colaboradores (2015). Os dois últimos critérios estão embasados nos princípios de sustentabilidade que estão em consonância com a nova era global do turismo, conforme Ryan (2002).

Tabela 3

Composição do IRC

\begin{tabular}{|cc|}
\hline Receita Corrente Líquida (RCL) per capita & IRC \\
0 a 750 & 10 \\
750,01 a 875 & 9 \\
875,01 a 1000 & 8 \\
1000,01 a 1125 & 7 \\
1125,01 a 1250 & 6 \\
1250,01 a 1375 & 5 \\
1375,01 a 1500 & 4 \\
1500,01 a 2000 & 3 \\
2000,01 a 3000 & 2 \\
Acima de 3000 & 1 \\
\hline
\end{tabular}

Fonte: Minas Gerais (2009).

Salientamos a importância da organização da gestão turística entre os critérios, bem como a proteção ao patrimônio cultural e ao meio ambiente. Vale ressaltar também que o ICMS Turístico - como política de descentralização de estado para municípios - resulta de um contexto, iniciado a partir da Constituição de 1988 e do Plano Nacional de Municipalização do Turismo (PNMT), na década de 1990, que incentivou a organização de circuitos turísticos regionais.

\subsection{Análise estatística}

Verifica-se a crescente participação dos municípios desde o início do incentivo (gráfico 1). No primeiro ano de repasse, apenas 44 cidades receberam o ICMS Turístico (apenas 10,55\% entre os 417 possíveis), ao passo que em 2014 tivemos 158 (atingindo 37,89\%). Isso significa que cada vez mais cidades se organizam em torno do turismo, e até o momento de elaboração do artigo 206 municípios já estavam cadastrados para repasse em 2015, atingindo 49,4\%. 
Gráfico 1

Municípios beneficiados por ano

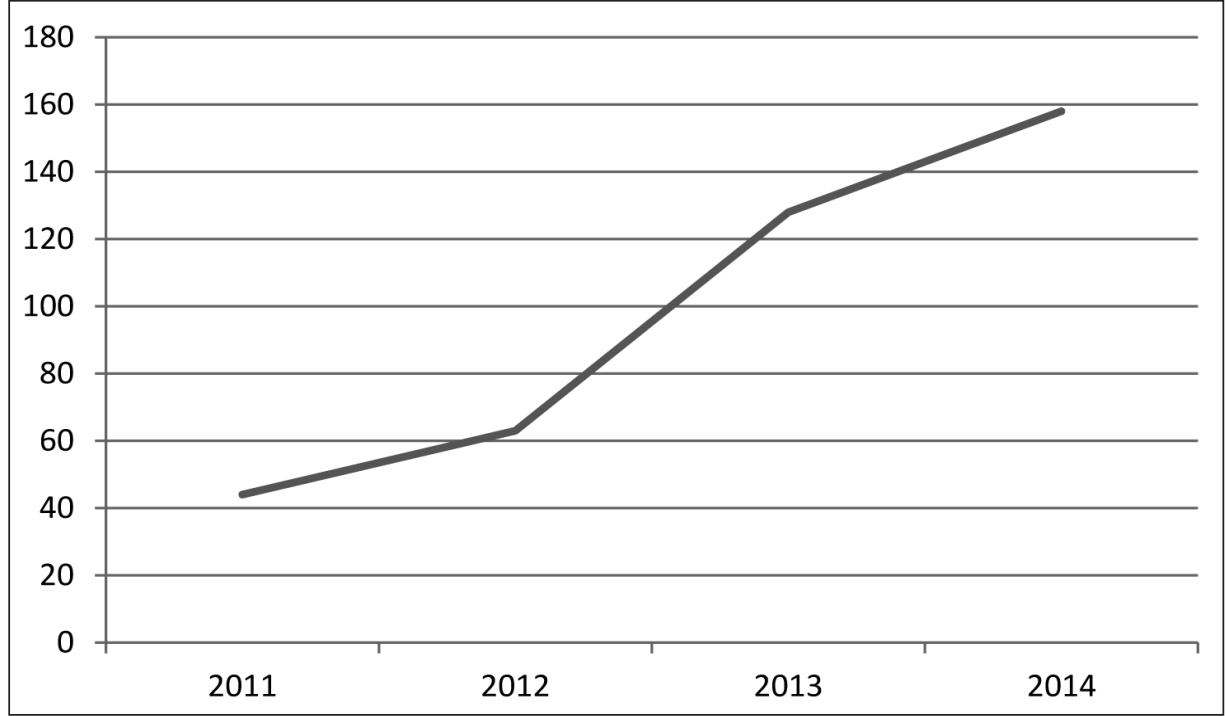

Fonte: Dados da pesquisa.

É possível verificar que, quanto maior o tamanho da cidade, mais adequado é o IIT que baseia a distribuição das receitas estaduais (tabela 4). No geral, o indicador criado pelo Governo do Estado para distribuir as receitas por meio do ICMS Turístico é uma boa ferramenta. A análise dos extremos do item 4.3 aliada às considerações se revela melhor porque o indicador tem mais consistência na medida em que cresce a quantidade populacional.

Tabela 4

Correlação de Pearson

\begin{tabular}{|c|c|c|c|c|}
\hline$(I C+I D)$ & Pequeno porte I & Pequeno porte II & Médio porte & Grande Porte \\
\hline Pequeno porte I & $\begin{array}{l}\text { FRACA } \\
-0,52\end{array}$ & - & - & - \\
\hline Pequeno porte II & - & $\begin{array}{c}\text { MODERADA } \\
-0,66\end{array}$ & - & - \\
\hline Médio porte & - & - & $\begin{array}{r}\text { ALTA } \\
-0,78\end{array}$ & - \\
\hline Grande Porte & - & - & - & $\begin{array}{c}\text { MUITO ALTA } \\
-0,93\end{array}$ \\
\hline
\end{tabular}

Fonte: Dados de pesquisa. 
Os dados das cidades de pequeno porte I apresentam uma grande dispersão, indicando que a distribuição do ICMS Turístico pode não ser uma boa ferramenta para esse grupo (gráfico 2). A análise qualitativa dos dados no item 4.3 deste artigo busca compreender com maior clareza esse fenômeno, e o tópico de discussão dos resultados propõe soluções acerca do problema.

Gráfico 2

Dispersão em cidades de pequeno porte I

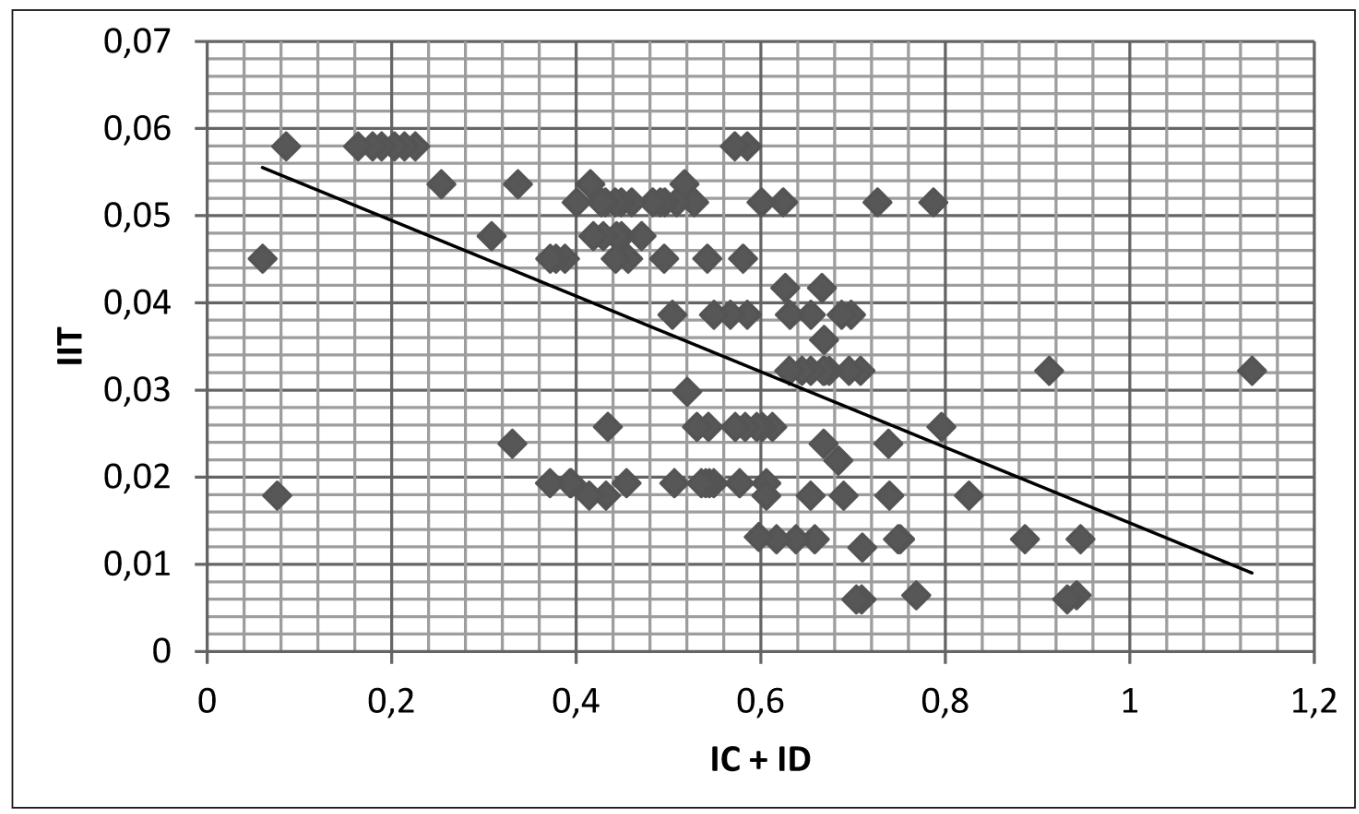

Fonte: Dados de pesquisa.

Entre os municípios de pequeno porte II a situação apresenta melhora, mas a correlação ainda é moderada (gráfico 3). Chamamos a atenção que, devido à complexidade dos dados, principalmente a Nota que compõe a fórmula do IIT pode desequilibrar a proporcionalidade, por isso, mesmo com correlação moderada $(0,66)$, é possível considerar a eficácia do ICMS Turístico nesse grupo.

Quanto maior o tamanho das cidades avaliadas, mais preciso o IIT para distribuição aos municípios mais necessitados (gráfico 4). Entre as cidades de médio porte encontramos dados ainda mais consistentes. Talvez o problema de micronumerosidade do grupo amostral tenha reduzido um pouco a correlação devido à presença de um outlier, mas não compromete a capacidade de redistribuição equânime almejada pela política, comprovada no grupo de análise. 
Gráfico 3

Dispersão em cidades de pequeno porte II

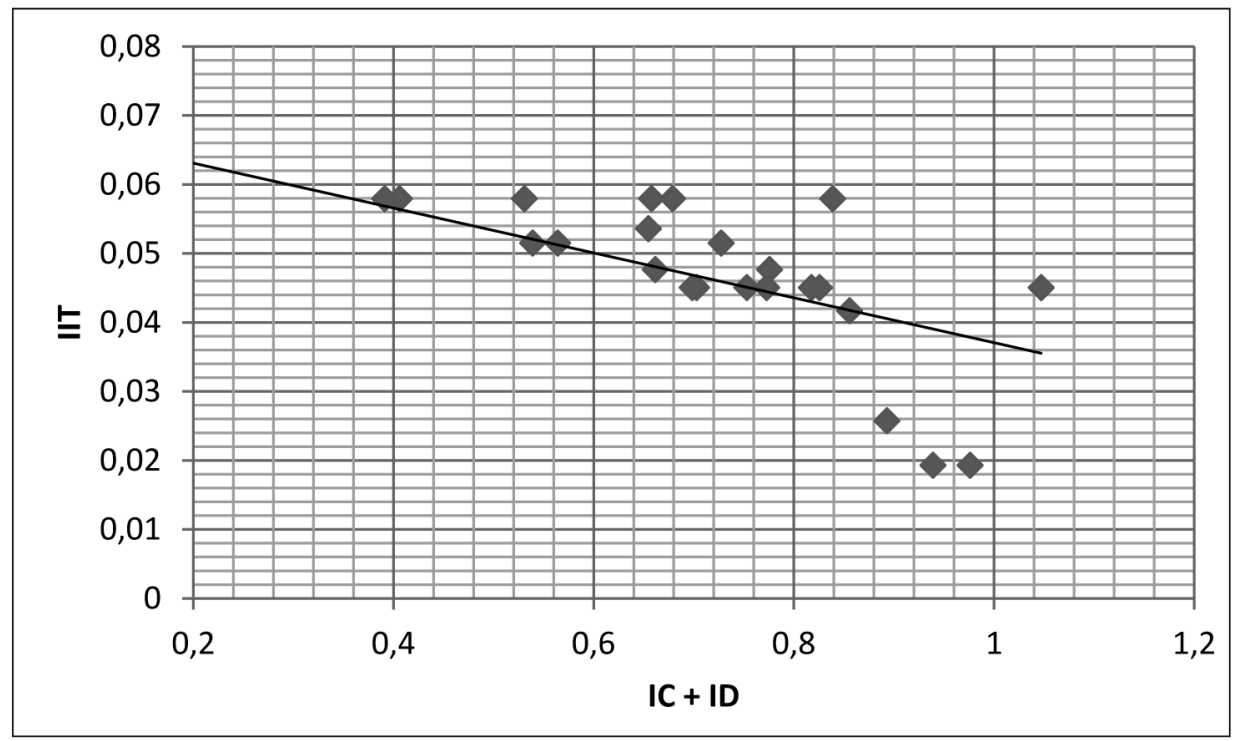

Fonte: Dados de pesquisa.

Gráfico 4

Dispersão em cidades de médio porte

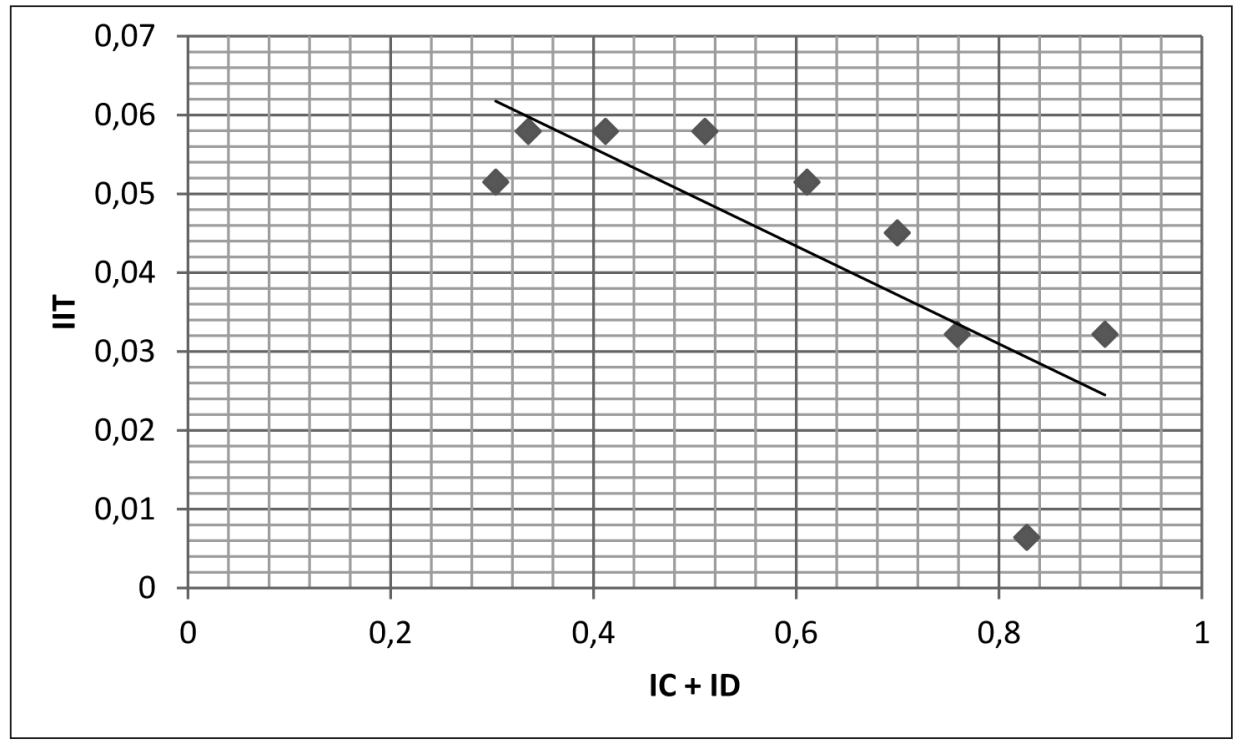

Fonte: Dados de pesquisa. 
O ICMS Turístico pode ser considerado um método justo de distribuição da arrecadação principalmente quando aplicados às cidades de grande porte (gráfico 5). Mesmo em um grupo amostral pequeno, apenas 13 municípios, com todos os possíveis problemas de micronumerosidade que poderiam ocorrer, qualquer outlier poderia desequilibrar os dados e reduzir a correlação, tal fato não ocorre.

Com isso, é possível inferir que os municípios de pequeno porte podem até conseguir uma gestão equilibrada tal qual evidenciado por Klering, Kruel e Stranz (2012), mas que a dependência turística pode não ser tão relevante para o contexto dos locais. Já os municípios participantes maiores e organizados possuem alta competitividade e dependência de atividades relacionadas com o turismo. Por isso, o ICMS Turístico é uma ferramenta de descentralização mais eficaz para cidades de grande porte, sendo necessária uma revisão de critérios para as cidades menores.

Gráfico 5

Dispersão em cidades de grande porte

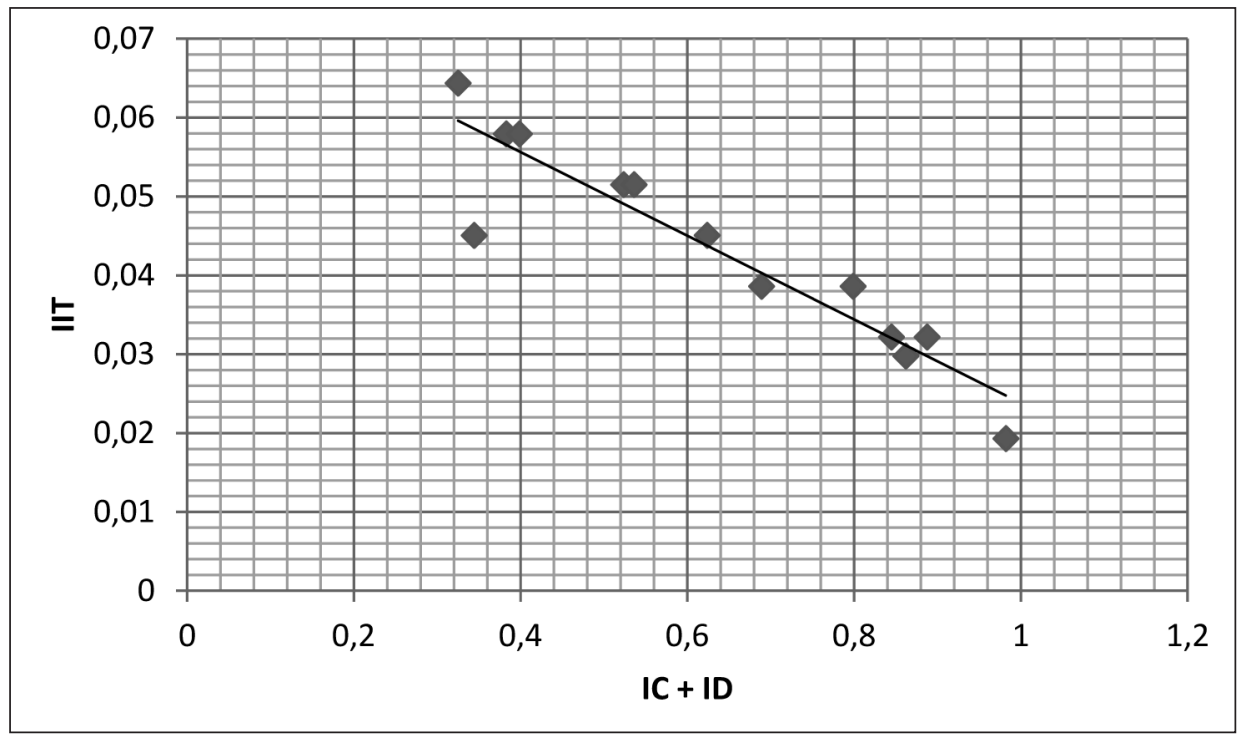

Fonte: Dados de pesquisa.

\subsection{Resumo qualitativo}

O intuito desta etapa de pesquisa consiste em comparar os extremos entre cada grupo de cidades pesquisadas de modo a identificar motivos para possíveis falhas na distribuição dos recursos do ICMS Turístico (quadros 2, 3, 4 e 5). Fica claro que, quanto menor o tamanho da cidade, mais distante a vocação turística do local com baixo Índice de Competitividade (IC) 
e Índice de Dependência do turismo (ID); por isso a grande dispersão entre as cidades de pequeno porte. Indicamos uma regra mais criteriosa para filiação dos municípios aos circuitos turísticos para que, de fato, apenas cidades com verdadeira vocação ou potencial turístico tenham direito à política. Possivelmente, uma "nota de corte", com grau de dependência e competitividade mínima, resolveria a situação e distribuiria melhor a receita.

Com isso, seria necessária outra política de distribuição de recursos aos municípios com baixa RCL per capita para que esta fosse utilizada de modo a considerar melhor a vocação do local.

Tanto a cidade com maior quanto a com menor dependência aliada à competitividade em turismo (Tiradentes $=1,13$ e Araponga $=0,059$ ) encontram-se entre os municípios de pequeno porte I (quadro 2). A distribuição dos recursos, em tese, deve contemplar mais os municípios com menor pujança econômica em turismo e que tivessem pouca RCL per capita, desde que a atividade turística seja, de fato, relevante para o local. Não é o que acontece na cidade de Araponga, por exemplo; acreditamos que essa distorção, que ocorre apenas no grupo de cidades de pequeno porte I, pode desvirtuar a finalidade da política.

Quadro 2

\section{Características dos municípios com menor e maior (ID + IC) - pequeno porte I}

\begin{tabular}{|c|c|c|}
\hline Município & Dados & Características do turismo \\
\hline Araponga & $\begin{array}{l}\text { 8.152 habitantes, sendo 62,7\% na } \\
\text { Zona Rural, a agricultura é a principal } \\
\text { atividade econômica, RCL per capita } \\
\text { 1498,23, ID 0,019 e IC 0,058 (me- } \\
\text { nor ID + IC do grupo de análise), e } \\
\text { IIT 0,045. }\end{array}$ & $\begin{array}{l}\text { Membro do Circuito Turístico Serras de Minas, com atrativos de monta- } \\
\text { nhismo, patrimônio de belezas naturais, com cachoeiras e arquitetura } \\
\text { religiosa. Não possui eventos relevantes em seu calendário turístico } \\
\text { e a atividade econômica relacionada ao turismo é baixa, com poucos } \\
\text { hotéis, alojamentos e restaurantes proporcionalmente à sua população } \\
\text { A maioria dos pontos é de visitação da própria comunidade local sem } \\
\text { grande inserção macrorregional. }\end{array}$ \\
\hline Tiradentes & $\begin{array}{l}6.961 \text { habitantes, sendo as principais } \\
\text { atividades ligadas à cultura barroca, } \\
\text { RCL per capita } 1872,13, \text { ID 0,18 e } \\
\text { IC 0,95 (maior ID + IC entre todos } \\
\text { OS } 158 \text { municípios pesquisados) e } \\
\text { IIT 0,032. }\end{array}$ & $\begin{array}{l}\text { Elevada rede de hotéis, pousadas, empresas e alta geração de empre- } \\
\text { go com o turismo. A cidade possui atividades ligadas ao ecoturismo, } \\
\text { diversas opções de passeios e eventos culturais, incluindo teatros } \\
\text { de marionetes, festival de gastronomia, mostra de cinema e turismo } \\
\text { religioso. Membro do circuito turístico Trilha dos Inconfidentes, explora } \\
\text { o forte apelo histórico, característico do local. }\end{array}$ \\
\hline
\end{tabular}

Fonte: IBGE (2010); Minas Gerais/Setur (2015).

A influência da identidade local possui grande impacto no turismo no caso de Tiradentes. Segundo Wang e Chen (2015), as regiões que conseguem essa identidade se sobressaem e, por esse motivo, tais localidades apresentam uma saída plausível em relação ao modelo de competitividade exacerbada da chamada "indústria turística". Essa característica de potencialidades locais e regionalismo também é encontrada no município de Camanducaia, que possui melhor (ID + IC) entre as cidades de pequeno porte II (quadro 3). Por outro lado, o município de Novo Cruzeiro não possui tal capacidade de exploração (pior ID + IC do grupo).

Tanto no caso de Araponga quanto de Novo Cruzeiro, a falta de vocação é perceptível. Apesar disso, os municípios foram capazes de organizar a gestão turística. Isso evidencia uma 
falha no processo de redistribuição do ICMS Turístico. A organização da gestão não deve ser o único critério de inclusão, ou seja, para receber verbas, o local deve gerar atividade econômica em níveis proporcionais. O referencial teórico evidenciou tal possibilidade, demonstrando que municípios pequenos apresentam bom desempenho em gestão, conforme Klering, Kruel e Stranz (2012).

Desse modo, é preciso considerar o contexto histórico da atividade turística. O conhecimento, por parte dos munícipes, é relevante para o fortalecimento da história local, e contribui para reforçar a autoestima e a atitude dos residentes. A comunidade local tende a se envolver mais em projetos de cunho regional cuja característica cultural é compreendida (Réau, 2015).

Quadro 3

Características dos municípios com menor e maior (ID + IC) - pequeno porte II

\begin{tabular}{|c|c|c|}
\hline Município & Dados & Características do turismo \\
\hline Novo Cruzeiro & $\begin{array}{l}30.725 \text { habitantes, principal atividade } \\
\text { econômica é o comércio, RCL per capita } \\
1185,86, \text { ID 0,007 e IC 0,08 (menor ID } \\
\text { + IC do grupo de análise), e IIT 0,058 } \\
\text { (elevadíssimo, com alta participação } \\
\text { na receita do ICMS turístico e pouca } \\
\text { vocação). }\end{array}$ & $\begin{array}{l}\text { Membro do Circuito Turístico das Pedras Preciosas, tendo } \\
\text { como principal atrativo o famoso festival da cachaça. Não } \\
\text { possui atividade econômica pujante relacionada com o } \\
\text { turismo, com poucos hotéis, alojamentos e restaurantes pro- } \\
\text { porcionalmente à sua população. Possui relevância histórica, } \\
\text { com patrimônios preservados, sendo o principal deles a antiga } \\
\text { ferrovia Bahia-Minas. }\end{array}$ \\
\hline Camanducaia & $\begin{array}{l}21.080 \text { habitantes, sendo as principais } \\
\text { atividades ligadas ao turismo e à indústria, } \\
\text { RCL per capita 1600,56 ID 0, } 1 \text { e IC 0,94 } \\
\text { (maior ID + IC do grupo) e IIT 0,045. }\end{array}$ & $\begin{array}{l}\text { O grande potencial da região é o distrito de Monte Verde, } \\
\text { com características paisagísticas semelhantes aos Alpes suíços, } \\
\text { montanhas, bosques de araucárias, gastronomia especial e } \\
\text { trilhas. Vasta rede de hotéis, pousadas e atividades de visitação } \\
\text { turística, artesanato. Pontos de cachoeira, além da gruta José } \\
\text { Pereira e o pico do Selado. Membro do Circuito Turístico Serras } \\
\text { Verdes do Sul de Minas. }\end{array}$ \\
\hline
\end{tabular}

Fonte: IBGE (2010); Minas Gerais/Setur (2015).

No grupo de cidades de médio porte destacamos Três Pontas (menor resultado) e Araxá (maior resultado). A economia diversificada não permite que a dependência do turismo seja muito forte em ambas as cidades (quadro 4). Apesar das diferenças entre elas, há uma confluência maior em infraestrutura da atividade turística. Por isso, nesse grupo, a política tem grande capacidade de distribuir maiores recursos aos municípios mais necessitados, e todos eles possuem infraestrutura e vocação turística, ou seja, o ICMS Turístico é efetivo como forma de descentralização das políticas de turismo.

A estrutura para atividade turística é relevante, mas os governos também devem preocupar-se com processos. Tal posicionamento exige do setor público um papel mais proativo na gestão do desenvolvimento do turismo formando um contexto denominado "Novo Regionalismo", onde o planejamento e a colaboração descentralizada aumentam a capacidade do turismo em gerar o bem-estar das pessoas (Shone e Memon, 2008). 
Quadro 4

\section{Características dos municípios com menor e maior (ID + IC) - médio porte}

\begin{tabular}{|c|c|c|}
\hline Município & Dados & Características do turismo \\
\hline Três Marias & $\begin{array}{l}53.850 \text { habitantes, econo- } \\
\text { mia diversificada, RCL per } \\
\text { capita } 2192,72, \text { ID 0,019 } \\
\text { e IC 0,28 (menor ID + IC } \\
\text { do grupo de análise), e IIT } \\
0,052\end{array}$ & $\begin{array}{l}\text { Membro do Circuito Turístico Vale Verde e Quedas D'água, o município já } \\
\text { possui uma infraestrutura local com hotéis e restaurantes aptos ao desen- } \\
\text { volvimento da atividade turística, restando então maior aproveitamento de } \\
\text { seu potencial. Pois a passagem do rio São Francisco, as belas cachoeiras } \\
\text { e o oásis do sertão inspiraram o escritor João Guimarães Rosa, em sua } \\
\text { obra Grande sertão: veredas. }\end{array}$ \\
\hline Araxá & $\begin{array}{l}93.672 \text { habitantes, sendo a } \\
\text { principal atividade ligada à } \\
\text { mineração, RCL per capita } \\
\text { 1940,39 ID 0,046 e IC 0,86 } \\
\text { (maior ID + IC do grupo) e } \\
\text { IIT 0,032. }\end{array}$ & $\begin{array}{l}\text { Membro do Circuito Turístico da Canastra, o município fortaleceu-se como } \\
\text { polo turístico na década de } 1940 \text { com a construção do Complexo Termal } \\
\text { - Grande Hotel e Balneário, lendas locais como o mito de dona Beja, } \\
\text { museus, gastronomia típica, achados paleontológicos e os eventos anuais a } \\
\text { seguir completam o potencial turístico local: campeonato internacional de } \\
\text { Voo Livre, campeonato internacional de Mountain Bike, evento de Carros } \\
\text { Antigos, Festival de Literatura, Páscoa lluminada, Festival Internacional de } \\
\text { Cultura e Gastronomia. }\end{array}$ \\
\hline
\end{tabular}

Fonte: IBGE (2010); Minas Gerais/Setur (2015).

A maior correlação encontrada foi no grupo de cidades de grande porte e os estudos qualitativos conseguem explicar melhor o fenômeno (quadro 5). A diferença qualitativa em termos turísticos entre os municípios de Coronel Fabriciano e Poços de Caldas deixa clara a efetividade do ICMS turístico como ferramenta de avaliação e distribuição de receitas para os municípios.

$$
\text { Quadro } 5
$$

\section{Características dos municípios com menor e maior (ID + IC) - grande porte II}

\begin{tabular}{|c|c|c|}
\hline Município & Dados & Características do turismo \\
\hline Coronel Fabriciano & $\begin{array}{l}103.694 \text { habitantes, economia diversifi- } \\
\text { cada, RCL per capita 1047,85, ID 0,038 } \\
\text { e IC 0,29 (menor ID + IC do grupo de } \\
\text { análise), e IIT 0,064. }\end{array}$ & $\begin{array}{l}\text { Membro do Circuito Turístico Mata Atlântica de Minas, possui } \\
\text { roteiros urbanos voltados para espaços culturais e religiosos, e } \\
\text { trilhas rurais nas cachoeiras da serra dos Cocais, com atrativos } \\
\text { para esportes radicais em Mountain Bike, escalada, trekking e } \\
\text { salto de paraquedas. Há uma vasta e densa rede de hotéis, } \\
\text { pousadas e restaurantes. }\end{array}$ \\
\hline Poços de Caldas & $\begin{array}{l}152.435 \text { habitantes, sendo as principais } \\
\text { atividades ligadas ao turismo e à indústria, } \\
\text { RCL per capita 2530, } 17 \text { ID 0,057 e IC } \\
\text { 0,92 (maior ID + IC do grupo) e IIT 0,02. }\end{array}$ & $\begin{array}{l}\text { A cidade "respira" turismo graças às termas, águas terapêuticas e } \\
\text { à grande "cultura turística" entre os habitantes. O calendário de } \\
\text { eventos apresenta: Sinfonia das Águas, Festa Uai, Feira Nacional } \\
\text { do Livro, Flipoços, Julho Fest, Festival Música nas Montanhas } \\
\text { e outros. Atrativos culturais, gastronômicos e belezas naturais } \\
\text { completam o potencial do município que é membro do Circuito } \\
\text { Turístico Caminhos Gerais. }\end{array}$ \\
\hline
\end{tabular}

Fonte: IBGE (2010); Minas Gerais/Setur (2015). 
Assim, os aspectos empíricos observados podem contribuir para a evolução dos estudos em duas correntes principais: políticas públicas e regionalização do turismo no estado de Minas Gerais; e para a discussão acerca do federalismo, pela apresentação de modelo de política que pode ser replicado em outras unidades federativas.

Na primeira abordagem, a utilização do ICMS Turístico para fortalecimento dos Circuitos Turísticos avança em termos de produção. Antes estudada sob os enfoques de governança, inovação social e participação (Gomes, Silva e Queiroz-Neto, 2006; Emmendoerfer et al., 2007; Gomes e Santos, 2007; Emmendoerfer, Silva e Lima, 2011), agora ganha contornos para análise da descentralização administrativa e de regionalização do turismo (Silva et al., 2012; Soares et al., 2012; Soares, Emmendoerfer e Monteiro, 2013; Fuchs e Oliveira, 2013; Sette, Valle e Coutinho, 2015).

Já o segundo bloco de contribuições incentiva o federalismo do Brasil, porém corrigindo distorções que promovem as desigualdades regionais. Nesse sentido, Saldanha (2009:357) afirma: "Aperfeiçoar a descentralização e corrigir seus defeitos transitam necessariamente na resolução dos principais dilemas federativos do Brasil".

\section{Considerações finais}

Em geral, a implantação do ICMS Turístico contribui para a regionalização do turismo de Minas Gerais e a sua aplicação fortalece os Circuitos Turísticos. Essa política é um modelo de gestão das regiões turísticas que segue as diretrizes do Programa de Regionalização do Turismo, estabelecido pelo Ministério do Turismo. Os Circuitos abrigam um conjunto de municípios de uma mesma região. É preciso que entre eles existam afinidades culturais, sociais e econômicas regionais de forma sustentável, consolidando uma identidade regional, com a participação de gestores públicos, iniciativa privada e sociedade civil (Minas Gerais/Setur, 2015).

Essas políticas regionalizadas e descentralizadas favorecem a manutenção cultural, proteção histórica em contraponto ao modelo de "industrialização do turismo" (Wang e Chen, 2015). Indicamos estudos em profundidade que analisem os circuitos turísticos, bem como as características locais, de modo a averiguar a contribuição dessas instituições.

Sem dúvida, o modelo adotado pelo Governo do Estado para a distribuição de receitas é mais equânime entre os municípios de maior porte, alocando recursos nas cidades mais necessitadas. Entretanto, há distorções em auxílios a municípios com baixa vocação turística, medida pelas atividades econômicas e geração de empregos em seus Índices de Dependência (ID). Reforçamos nosso pensamento de que esses locais deveriam participar de outra política de distribuição de recursos, não necessariamente com aplicabilidade exclusiva ao turismo, o que tornaria ainda melhor a contribuição do ICMS Turístico.

A descentralização das políticas públicas do turismo reforça a ideia de regionalização e, consequentemente, de relacionamento, considerada por muitos especialistas um futuro viável para a atividade (Silva et al., 2015b). O turismo é essencialmente orientado para a identidade local, em diferentes escalas. Os governos regionais devem esforçar-se em conciliar tais características para uma linguagem global que atraia diferentes públicos (Dredge e Jenkins, 2010). 
Ao analisar a política, é possível afirmar que o ICMS Turístico possui metodologia de avaliação consistente capaz de detectar, entre os municípios organizados pelo turismo, aqueles mais necessitados, gerando uma externalidade fiscal positiva, algo jamais visto na literatura acadêmica. Por isso, de elevada contribuição teórica e empírica.

Mais especificamente, apenas para o grupo de municípios de pequeno porte I, indicamos uma espécie de "nota de corte" em termos de dependência do turismo, ao passo que criar critérios em demasia poderia descaracterizar o intuito de regionalismo do projeto.

Conforme Saldanha (2009), a federação brasileira sempre teve dificuldades para responder corretamente aos objetivos desse tipo de organização política. Desse modo, os estados vêm procurando aprofundar suas estratégias para descentralizar e regionalizar, por meio de parcerias com os municípios. Fica evidente que, em uma organização político-administrativa que adota o federalismo municipalista, como é o caso do Brasil, é preciso que mais responsabilidades para os municípios sejam acompanhadas, proporcionalmente, de maiores receitas. É possível que os preceitos adotados pelo ICMS Turístico, como regionalização de ações e a obrigatoriedade de organização da gestão, constituam uma saída viável para a sustentabilidade do atual pacto federativo.

A redistribuição de recursos para os municípios organizados incentiva a melhoria da gestão turística, mas é importante notar que as contribuições do trabalho vão além disso: demostra que esse tipo de política descentralizadora pode se transformar em modelo para reverter a tendência centralizadora, ainda presente em nossa administração pública (Saldanha, 2009; Arretche, 2012).

Portanto, os resultados apontam para a efetiva contribuição da política descentralizada, por meio do ICMS Turístico, com a necessidade de pequenos ajustes em termos de vocação e critérios para grupos específicos de municípios por parte do governo estadual. Num contexto onde poucos governos estaduais se engajam, efetivamente, na promoção do turismo, a descentralização de receitas do estado para os municípios configura um passo importante para efetivação de políticas públicas para a área (Silva et al., 2015b).

\section{Referências}

ARRETCHE, Marta. Democracia, federalismo e centralização no Brasil. Rio de Janeiro: Fiocruz, 2012. BAHL, Miguel. Agrupamentos turísticos municipais. Curitiba: Protexto, 2004.

BARBOSA, Fernando de H. Federalismo fiscal, eficiência e equidade: uma proposta de reforma tributária. Brasília: Sinafresp/Fenafisco, 1998.

BESLEY, Timothy J.; ROSEN, Harvey S. Vertical externalities in tax setting: evidence from gasoline and cigarettes. Journal of Public Economics, v. 70, n. 3, p. 383-398, abr./jun. 1998.

BEUREN, Ilse M.; ALMEIDA SANTOS, Paulo S. Relação entre transparência e reputação governamental. Revista de Globalización, Competitividad y Gobernabilidad, v. 7, n. 3, p. 89-102, set./dez. 2013. 
BORGES, André. The political consequences of center-led redistribution in Brazilian federalism: the fall of subnational party machines. Latin American Research Review, v. 46, n. 3, p. 21-45. 2011. CABRERA, G. Subsídios à formulação da política nacional de turismo. São Paulo: Anhembi Morumbi, 2002.

CAMARGO, Aspasia B. A. Atualidade do federalismo: tendências internacionais e a experiência brasileira. In: VERGARA, Sylvia C.; CORRÊA, Vera L. A. (Org.). Propostas para uma gestão pública municipal efetiva. 2. ed. Rio de Janeiro: Fundação Getulio Vargas, 2004. p. 39-47.

CARTER, David P. et al. Assessing policy divergence: how to investigate the differences between a law and a corresponding regulation. Public Administration, v. 93, n. 1, p. 159-176, jan./mar. 2015.

CHANG, Tou C. Regionalism and tourism: exploring integral links in Singapore. Asian Pacific Viewpoint, v. 39, n. 1, p. 73-94, 1998.

DREDGE, Dianne; JENKINS, John. Destination place identity and regional tourism policy. Tourism Geographies: An International Journal of Tourism Space, Place and Environment, v. 5, n. 4, p. 383407, 2010.

EMMENDOERFER, Luana et al. A formação dos circuitos turísticos mineiros: uma política pública descentralizada e democratizante? Revista Acadêmica do Observatório de Inovação do Turismo, v. 2, n. 4, p. 1-18, 2007.

EMMENDOERFER, Magnus L.; SILVA, Fernanda C.; LIMA, Afonso A. T. F. C. Evidências de inovação social na gestão pública do turismo em Minas Gerais-Brasil: o modelo de circuitos turísticos em análise. PASOS. Revista de Turismo y Patrimonio Cultural, v. 9, n. 2, p. 397-410, 2011.

FERREIRA, Ivan F. S.; BUGARIN, Mauricio S. Transferências voluntárias e ciclo político-orçamentário no federalismo fiscal brasileiro. Revista Brasileira de Economia, Rio de Janeiro, v. 61, n. 3, p. 271-300, 2007.

FIRJAN. Federação das Indústrias do Rio de Janeiro. Índice Firjan de desenvolvimento municipal dados consolidados 2014 — ano base 2011. 2014. Disponível em: <www.firjan.org.br/ifdm>. Acesso em: 3 mar. 2015.

FLOWERS, Marilyn R. Shared tax sources in a Leviathan model of federalism. Public Finance Quarterly, v. 16, n. 1, p. 67-77, 1988.

FREDRIKSSON, Per G.; MAMUN, Khawaja A. Vertical externalities in cigarette taxation: do tax revenues go up in smoke? Journal of Urban Economics, v. 64, n. 1, p. 35-48. 2008.

FUCHS, Andréa M. S. L.; OLIVEIRA, Frederico F. ICMS turístico e novas possibilidades de desenvolvimento regional para o estado de Minas Gerais. Anais Brasileiros de Estudos Turísticos, v. 2, n. 2, p. 54-64, 2013.

GOMES, Bruno M. A.; SANTOS, Antônio C. Influências das políticas públicas de turismo nas transações entre os agentes: uma análise sob a ótica da ECT. Revista Brasileira de Pesquisa em Turismo, v. 1, n. 2, p. 72-100, 2007. 
GOMES, Bruno M. A.; SILVA, Marcelo A. C.; QUEIROZ NETO, Exzolvildrez. A ação coletiva em regiões turísticas: um estudo dos circuitos turísticos de Minas Gerais. Turismo: Visão e Ação, v. 8, n. 2, p. 323-330, 2006.

HOYT, William H. Tax policy coordination, vertical externalities, and optimal taxation in a system of hierarchical governments. Journal of Urban Economics, v. 50, n. 3, p. 491-516. 2001.

HOYT, William H.; JENSEN, Richard A. Precommitment in a system of hierarchical governments. Regional Science and Urban Economics, v. 26, n. 1, p. 481-504. 1996.

IBGE. Instituto Brasileiro de Geografia e Estatística. Censo 2010. 2010. Disponível em: <www.ibge. gov.br>. Acesso em: 4 mar. 2015.

JOHN, Peter. Analysing public policy. 2. ed. Nova York: Pinter, 2012.

KEEN, Michael J.; KOTSOGIANNIS, Christos. Does federalism lead to excessively high taxes? The American Economic Review, v. 92, n. 1, p. 363-370, 2002.

KLERING, Luis R.; KRUEL, Alexandra J.; STRANZ, Eduardo. Os pequenos municípios do Brasil uma análise a partir de índices de gestão. Análise - Revista de Administração da PUCRS, v. 23, n. 1, p. 31-44, 2012.

MAY, Peter J.; JOCHIM, Ashley E. Policy regime perspectives: policies, politics, and governing. The Policy Studies Journal, v. 41, n. 3, p. 426-452, 2013.

MINAS GERAIS. Governo do Estado de Minas Gerais. Lei Estadual nº 18.030: dispõe sobre a distribuição da parcela da receita do produto da arrecadação do ICMS pertencente aos Municípios. Palácio da Liberdade, Belo Horizonte, 12 jan. 2009. p. 21.

MINAS GERAIS/SETUR. Governo do Estado de Minas Gerais: Secretaria de Turismo. Observatório do turismo da Secretaria Estadual de Turismo, 2015. Disponível em: <www.minasgerais.com.br/ observatorioturismomg/>. Acesso em: 12 mar. 2015.

OLIVEIRA, Cristiano A.; MARQUES JÚNIOR, Liderau S.; LAGEMANN, Eugenio. Fiscal policy as a game among the Union, the states and municipalities in Brazilian fiscal federalism. Economic Analysis of Law Review, v. 3, n. 2, p. 206-227, 2012.

PATTON, Michael Q. Practical evaluation. Beverly Hills: Sage Publications, 1982.

PEREIRA, Cássio A. S. A trajetória da política de turismo em Minas Gerais e o papel do poder legislativo em sua transformação. Dissertação (mestrado em ciência política) - Universidade Federal de Minas Gerais, Belo Horizonte.

RÉAU, Bertrand. The historical social science of tourism. Journal of Tourism History, v. 6, n. 2, p. 210-222, 2015.

RYAN, Chris. Equity, management, power sharing and sustainability-issues of the "new tourism". Tourism Management, v. 23, n. 1, p. 17-26, 2002.

SALDANHA, Ana C. Estado federal e descentralização: uma visão crítica do federalismo brasileiro. Revista Sequência, v. 1, n. 59, p. 327-360, dez. 2009. 
SETTE, Isabela R.; VALLE, Maria I. M.; COUTINHO, Marcela P. C. O programa de regionalização do turismo de Minas Gerais: uma abordagem da política pública estadual de turismo. Revista Turismo em Análise, v. 25, n. 3, p. 608-627, 2015.

SHONE, Michael C.; MEMON, P. A. Tourism, public policy and regional development: a turn from neo-liberalism to the new regionalism. Local Economy, v. 23, n. 4, p. 290-304, 2008.

SILVA, Fernanda C. et al. A política de circuitos turísticos de Minas Gerais: uma avaliação baseada na percepção de agentes estratégicos. PASOS. Revista de Turismo y Patrimonio Cultural, v. 10, n. 3, p. 369-379, 2012.

SILVA, Giuliano A. B. et al. Avaliação das políticas de industrialização: o caso de Araxá-MG. Cadernos Gestão Pública e Cidadania, v. 20, n. 67, p. 235-257, jul./dez. 2015a.

SILVA, Giuliano A. B. et al. Destinos indutores de turismo regional como política de governabilidade estadual no Brasil: análise dos estados de Minas Gerais e Bahia a partir do Índice Firjan de Desenvolvimento Municipal (IFDM). Revista de Globalización, Competitividad y Gobernabilidad, v. 9, n. 2, p. 76-88, maio/ago. 2015b.

SOARES, Érica B. S.; EMMENDOERFER, Magnus L.; MONTEIRO, Lara P. Gestão pública no turismo e o desenvolvimento de destinos turísticos em um estado da federação brasileira: uma análise do planejamento estratégico do turismo em Minas Gerais (2007-2010). Tourism \& Management Studies, v. 9, n. 2, p. 50-56, 2013.

SOARES, Érica B. S. et al. ICMS turístico e conselhos municipais de turismo: um estímulo à participação social em prol do desenvolvimento turístico em destinos indutores de Minas Gerais? Cadernos Gestão Pública e Cidadania, v. 18, n. 61, p. 303-321, 2012.

WAMPLER, Brian. Entering the State: Civil society activism and participatory governance in Brazil. Political Studies, v. 60, n. 1, p. 341-362, 2012.

WANG, Suosheng; CHEN, Joseph S. The influence of place identity on perceived tourism impacts. Annals of Tourism Research, v. 52, n. 1, p. 16-28, 2015.

WEIBLE, Christopher M. Advancing policy process research. In: SABATIER, Paul; WEIBLE, Christopher M. (Ed.). Theories of the policy process. Boulder: Westview Press, 2014. p. 391-407.

WEIMER, David L.; VINING, Aidan R. Policy Analysis: Concepts and Practice. 4. ed. Upper Saddle River, NJ: Prentice Hall, 2005.

Giuliano Alves Borges e Silva é mestre e doutor pelo Programa de Pós-Graduação em Administração de Organizações da FEA-RP da Universidade de São Paulo (USP), membro do Centro de Estudos em Gestão e Políticas Públicas Contemporâneas (GPUBLIC). E-mail: nanoabs@gmail.com.

João Luiz Passador é professor associado do Departamento de Administração da FEA-RP da Universidade de São Paulo (USP), coordenador do Centro de Estudos em Gestão e Políticas Públicas Contemporâneas (GPUBLIC). Email: jlpassador@usp.br. 